Review Article

\title{
A Brief Review of Fungal Infection- Pityriasis Versicolor
}

Dr. Lalita Bansal ${ }^{1 *}$, Dr. Ashish Dhiman
${ }^{1}$ Medical Officer (OBG) R.H. Kullu Himach
${ }^{2}$ Medical Officer (General Surgery), R.H. K
Article History
Received: 13.11.2021
Accepted: 09.01.2022
Published: 21.01 .2022
Journal homepage:
https://www.easpublisher.com
Quick Response Code

Copyright (C) 2022 The Author(s): This is an open-access article distributed under the terms of the Creative Commons Attribution 4.0 International License (CC BY-NC 4.0) which permits unrestricted use, distribution, and reproduction in any medium for non-commercial use provided the original author and source are credited.

\section{INTRODUCTION}

Fungal infections of the skin are also known as 'mycoses'. They are common and generally mild. Nevertheless, in very sick or otherwise immune suppressed people, fungi can sometimes cause serious disease [1].

\section{Characteristics of fungi}

Fungi are parasites or saprophytes i.e. they live off living or dead organic matter. Mycologists identify and classify fungi according to their appearance by microscopy and in culture, and by the method of reproduction, which may be sexual or asexual. Growing fungi have branched filaments called hyphae, which make up the mycelium (like branches are part of a tree). Some fungi are compartmented by cross-walls (called septae). Arthrospores are made up of fragments of the hyphae, breaking off at the septae. Asexual spores (conidia) form on conidiophores. The sexual reproductive phase of many fungi is unknown; these are 'fungi imperfecta' and include those which infect humans. Yeasts form a subtype of fungus characterised by clusters of round or oval cells. These bud out similar cells from their surface to divide and propagate. In some circumstances they form a chain of cells called a pseudomycelium $[2,3]$.

\section{Superficial fungal infections}

These affect the outer layers of the skin, the nails and hair. The main groups of fungi causing superficial fungal infections are [4]:

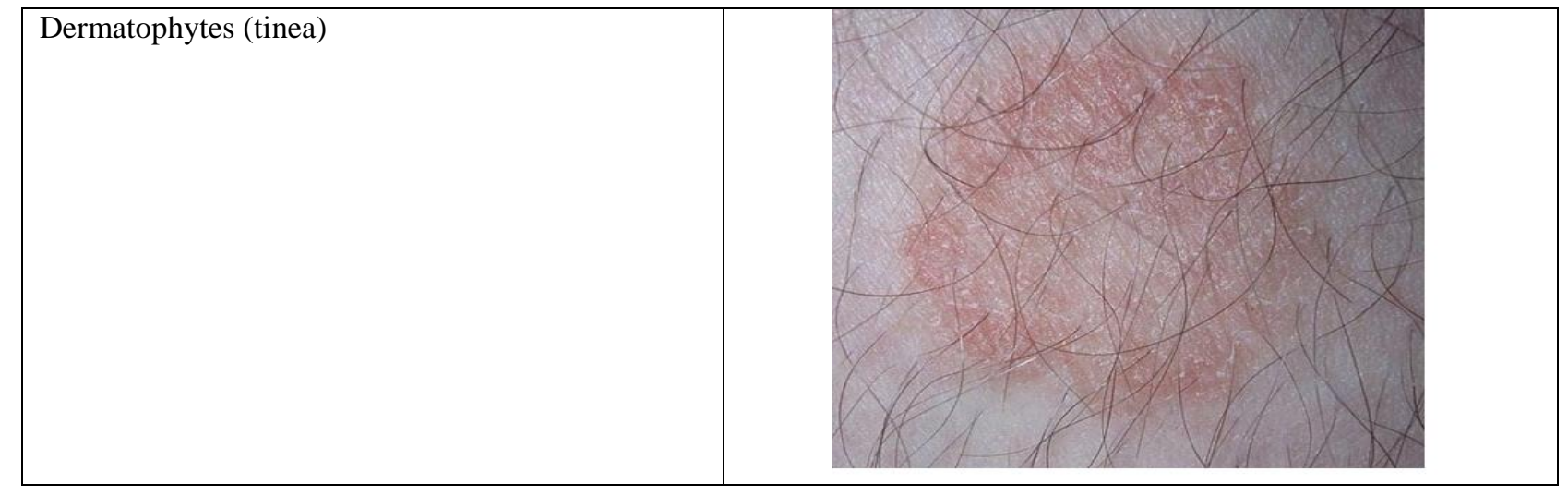

*Corresponding Author: Dr. Lalita Bansal 


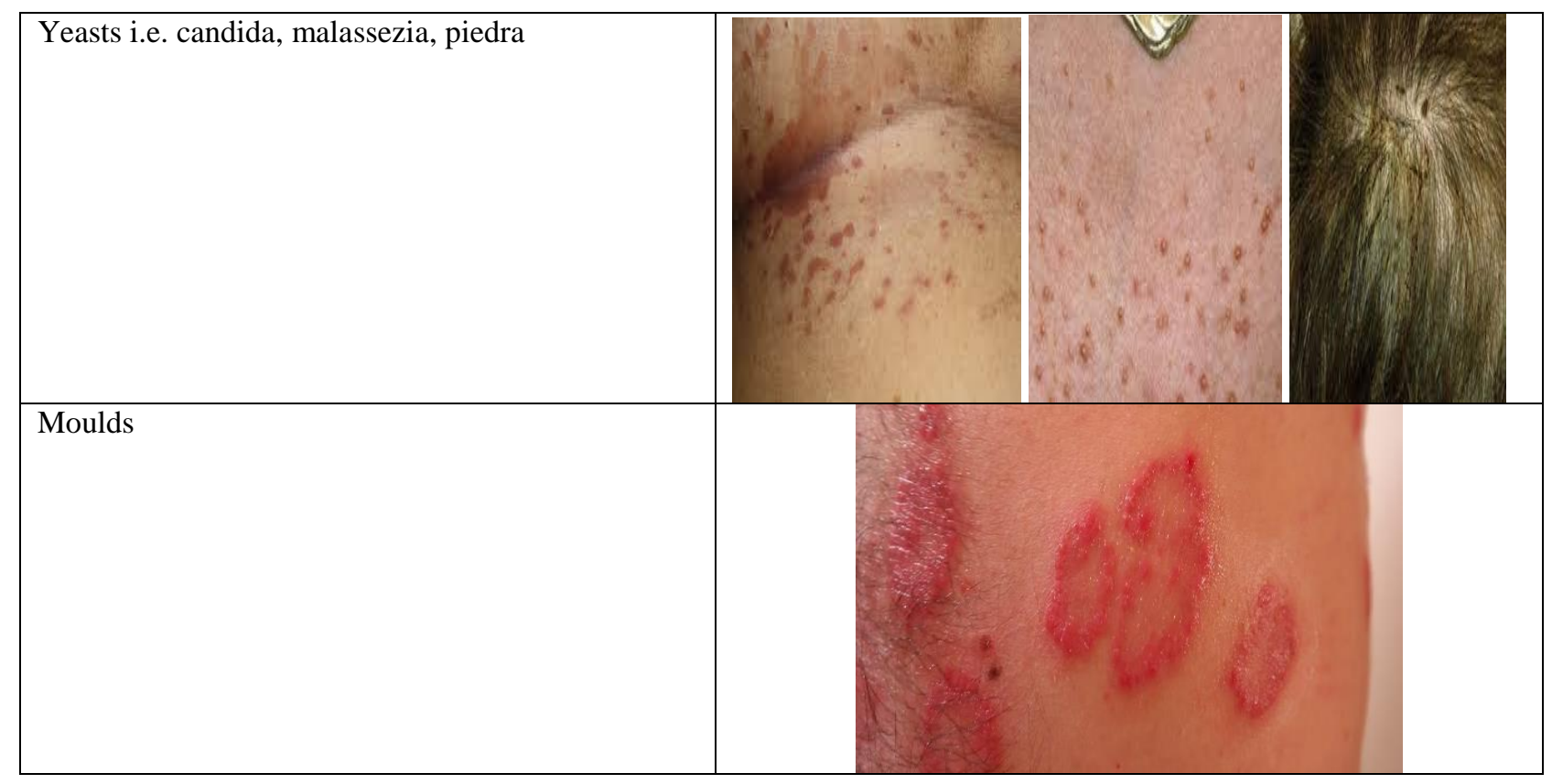

\section{Subcutaneous fungal infections}

These engage the deeper layers of the skin (the dermis, subcutaneous tissue and even bone). The causative organisms normally live in the soil living on rotting vegetation. They can get pricked into the skin as a result of an injury but usually stay localised at the site of implantation. Deeper skin infections include: Mycetoma and Chromoblastomycosis.

\section{Systemic fungal infections}

Systemic mycoses may result from breathing in the spores of fungi, which normally live in the soil or rotting vegetation or as opportunistic disease in immune compromised individuals.

\section{Inhaled fungal infection}

Although uncommon, some may infect healthy individuals. The result is most often a mild infection and long lasting resistance to further attack, but occasionally these infections are more serious and chronic (especially in the immune suppressed). The organisms causing systemic fungal infections include: Histoplasmosis and Coccidioidomycosis (North and South America).

\section{Opportunistic infection}

Serious illness and debility

Cancer or leukaemia

Diabetes mellitus

Transplant

Massive doses of antibiotics

Parenteral nutrition

Drug addiction and Infections with human immunodeficiency virus (HIV)

Other systemic mycoses only infect those who are already sick or with an immunodeficiency disorder i.e. they are 'opportunists'. Repeated infection may occur. Risks for systemic mycoses include:

\section{Opportunistic fungal infections include [5]}

Aspergillosis (found everywhere)

Mucormycosis

Cryptococcosis (where there are pigeon droppings)

Trichosporon beigelii

Pseudallescheria boydii.

\section{Pityriasis Versicolor [4]}

Pityriasis versicolor is a widespread yeast infection of the skin, in which flaky discoloured patches appear on the chest and back. The idiom pityriasis is used to explain skin conditions in which the scale appears similar to bran. The multiple colours of pityriasis versicolor give rise to the second part of the name, versicolor. Pityriasis versicolor is often called tinea versicolor, though the term tinea should strictly be used for dermatophyte fungus infections [6].

\section{Etiology}

Malassezia is a genus with 13 species. The yeasts are round, oval, or cylindrical in shape, with monopolar budding and sizes ranging from 2.5 to 8 metres depending on the species. $M$ furfur, $M$ pachydermatis, $M$ sympodialis, $M$ globosa, $M$ sloffiae, 
$M$ restricta, and $M$ mobtusa were the first seven species identified based on morphologic, biochemical, and physiologic characteristics. 33 In recent years, molecular techniques have shown the existence of six other species: $M$ dermatis, $M$ japonica, Myamatoensis, $M$ equine, $M$ caprae, and $M$ nana. Several of the latter taxa are most likely variants of already known species [7].

\section{Symptoms}

Generally oval or irregularly-shaped spots of $1 / 4$ to 1 inch $(0.6$ to $2.5 \mathrm{~cm})$ in diameter, often merging to form a larger patch, Occasional fine scaling of the skin producing a very superficial ash-like scale ,Pale, dark tan, or pink in color, with a reddish undertone that can darken when the patient is overheated, such as in a hot shower or during/after exercise, Sharp border and sometimes harsh "pin-prick" itching in the affected areas; usually when the person's body temperature is elevated by exercise or a hot/warm environment, but the person hasn't started sweating yet. Once sweating begins the "pin-prick" itching subsides.

These spots commonly affect the back, underarm, upper arm, chest, lower legs, and neck. Occasionally it can also be present on the face. The yeasts can often be seen under the microscope within the lesions and typically have a so called "spaghetti and meat ball appearance as the round yeasts produce filaments. In people with dark skin tones, pigmentary changes such as hypopigmentation (loss of color) are common, while in those with lighter skin color, hyperpigmentation (increase in skin color) are more common. These discolorations have led to the term "sun fungus.

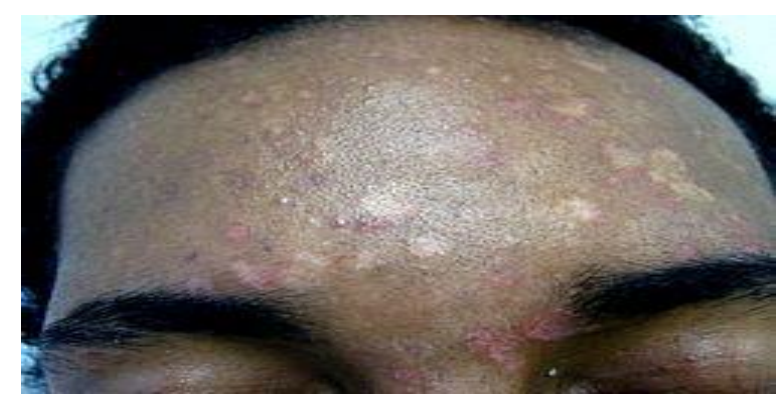

Pityriasis versicolor commonly causes hypopigmentation in people with dark skin tones

\section{Tinea versicolor}

The fungus Malassezia is a type of yeast originates on the surface of the skin. It usually doesn't cause any health problems. In fact, many of the microbiota (or microscopic organisms), including yeasts like Malassezia, that live in large communities on your skin aid protect you from infections and other pathogens that can cause harm or disease. They live beside your body's cells in symbiotic associate, with skin cells and tiny organisms supporting and benefiting each other.

Factors may endorse the growth of this yeast on the skin, including: hot and humid weather, excessive sweating, oily skin, a weakened immune system and hormonal changes $[8,9]$.

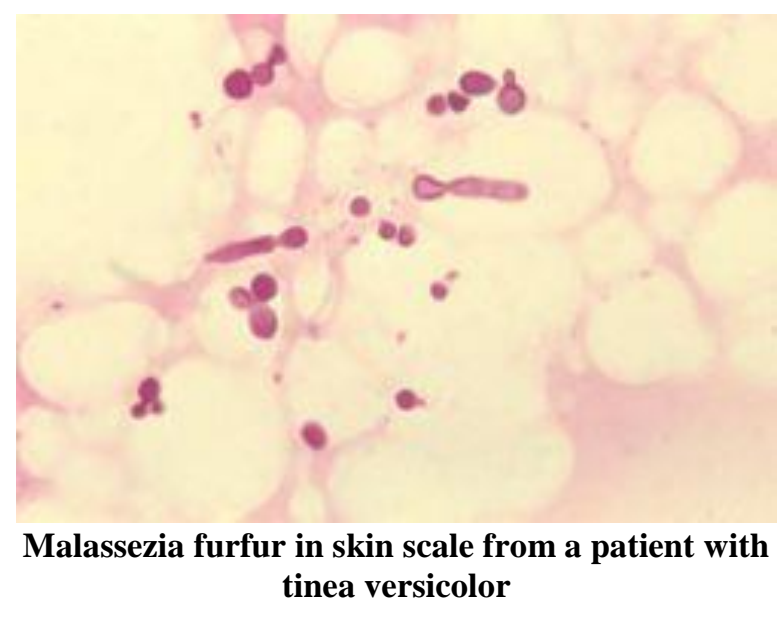

Treatments for tinea versicolor include

Tinaderm (Tolnaftate topical solution). Its composition is $10 \mathrm{mg}$ of Tolnaftate USP in Polyethylene and Glycol 400 USP NF base q.s.

Antifungal medications containing 2.5\% selenium sulfide (Selsun Extra Strength shampoo) are often recommended. Selsun Blue works for some people, but not all, because it only contains $1 \%$ selenium sulfide. Preparations containing more than $1 \%$ selenium sulfide are considered prescription strength. Products that contain $1 \%$ selenium sulfide include [ZunSpot] medicated cream. Ketoconazole (Nizoral ointment and shampoo) is another treatment. It is normally applied to dry skin and washed off after 10 minutes, repeated daily for 2 weeks. Ciclopirox (Ciclopirox olamine) is an alternative treatment to ketoconazole as it suppresses growth of the yeast Malassezia furfur. Initial results show similar efficacy to ketoconazole with a relative increase in subjective symptom relief due to its inherent anti-inflammatory properties [9]. Other topical antifungal agents such as clotrimazole, miconazole or terbinafine are less widely recommended [citation needed]. Additionally, hydrogen peroxide has been known to lessen symptoms, and on certain occasions, remove the problem, although permanent scarring occurs with this treatment.Clotrimazole $(1 \%)$ is also used combined with selenium sulfide (2.5\%) (Candid-TV) [10]. 


\section{Drawbacks}

\begin{tabular}{|l|l|}
\hline Topical antifungal medicines & Oral antifungals \\
\hline & abdominal pain \\
Itching & diarrhoea \\
a mild burning sensation & headache \\
Redness & a rash \\
& indigestion \\
\hline
\end{tabular}

AVAILABLE TREATMENT: Common Antifungal Medications and Their Forms

\begin{tabular}{|l|l|l|l|l|l|l|}
\hline Agent & $\begin{array}{l}\text { Rx or } \\
\text { OTC }\end{array}$ & $\begin{array}{l}\text { Solution } \\
\text { or spray* }\end{array}$ & Lotion $\dagger$ & Cream $\neq$ & $\begin{array}{l}\text { Gel or } \\
\text { ointment } \S\end{array}$ \\
\hline Tolnaftate (Tinactin) & OTC & Yes & Yes & Yes & Yes & No \\
\hline Haloprogin (Halotex) & $\mathrm{Rx}$ & Yes & No & Yes & No & No \\
\hline Ciclopirox (Loprox; Penlac|l) & $\mathrm{Rx}$ & Lacquer & Yes & Yes & No & No \\
\hline Clotrimazole (Lotrimin) & OTC & Yes & Yes & Yes & No & No \\
\hline Miconazole (Micatin) & OTC & Yes & Yes & Yes & No & Yes \\
\hline Ketoconazole (Nizoral) & $\mathrm{Rx}$ & Shampoo & No & Yes & No & No \\
\hline Sulconazole (Exelderm) & $\mathrm{Rx}$ & No & No & Yes & No & No \\
\hline Oxiconazole (Oxistat) & $\mathrm{Rx}$ & No & Yes & Yes & No & No \\
\hline Econazole (Spectazole) & $\mathrm{Rx}$ & No & No & Yes & No & No \\
\hline Butenafine (Mentax) & $\mathrm{Rx}$ & No & No & Yes & No & No \\
\hline Naftifine (Naftin) & $\mathrm{Rx}$ & No & No & Yes & Yes & No \\
\hline Terbinafine (Lamisil) & $\mathrm{Rx}$ & Yes & No & Yes & No & No \\
\hline Clotrimazole/BMD (Lotrisone) & $\mathrm{Rx}$ & No & No & Yes & No & No \\
\hline
\end{tabular}

- $\quad \mathrm{Rx}=$ prescription; OTC $=$ over-the-counter; $\mathrm{BMD}$ $=$ betamethasone dipropionate.

- *-Powders and sprays may be used to prevent reinfection.

- $\quad \dagger$-Use lotions in intertriginous or hairy areas and on oozing lesions.

- \$-Use creams on non-oozing and moderately scaling lesions.

- $\quad \S$-Use ointments on hyperkeratotic lesions.

- $\|$-Ciclopirox lacquer (Penlac) is approved for treatment of onychomycosis but has limited efficacy.

- $\quad$ Adapted with permission from Diehl KB. Topical antifungal agents: an update. Am Fam Physician 1996; 54:1689.

\section{Novel Drug delivery system for the antifungal agents}

Several factors influence the design and development of medicinal agent formulations and delivery methods. The link between formulations, mode of delivery, pharmacokinetics, toxicity, and therapeutic indication must be carefully balanced to ensure the successful creation of appropriate drug delivery systems. Antifungal medications should be provided either locally or systemically to remove fungal infection. Antifungals have been administered by routes other than those for which they were designed or licenced in an attempt to provide targeted therapy, reduce side effects, and increase drug penetration into specific infection areas such as the central nervous system, lungs, and peritoneum4. Various antifungal formulation with new approaches available like Liposomal Amphotericin B complex (L-AmB),
Nanocochleates, Nanosphere, Parental microsphere etc [11].

\section{Prevention Pityriasis Versicolor $[12,15]$}

Some people appear to be more susceptible to this yeast-like germ proliferating on their skin, and the rash may reoccur after therapy. Applying one of the above shampoos on your skin every 2-4 weeks is another option. This may keep the germ at bay or prevent the numbers from rising, preventing the rash from reappearing. If you have a lot of recurrences, you can be advised to take antifungal medications for one day every month as a prophylactic step.

\section{CONCLUSION}

For decades, the research of the pathogenesis of most fungal diseases has been neglected. One of the reasons is that many fungi can produce the same disease, as observed in dermatophytoses and TV caused by a variety of Malassezia yeast species. Despite this, we have gained a better understanding of the pathophysiology of these superficial mycoses because to a number of significant recent developments in the field. Detailed knowledge of the mechanisms underlying dermatophytes or Malasseziaspp adhesion, the molecular patterns associated with these pathogens, the type of Toll receptors they bind to, and the mechanisms by which some fungi modulate the local or general adaptive immune response could be useful in the development of new prevention methods and the production of new therapeutic agents. 


\section{REFERENCE}

1. Wang, N.X., von Recum, H.A. (2011). "AffinityBased Drug Delivery". Macromol Biosci, 11; 321332. doi:10.1002/mabi.201000206.

2. Bertrand, N., Leroux, J.C. (2011). "The journey of a drug carrier in the body: an anatomophysiological perspective". Journal of Controlled Release. doi:10.1016/j.jconrel .2011.09. 098

3. Baldauf; Palmer, J. D. (1993). "Animals and fungi are each other's closest relatives: congruent evidence from multiple proteins". Proceedings of the National Academy of Sciences of the United States of America, 90(24); 11558-11562. Bibcode 1993PNAS.9011558B.doi:10.1073/pnas.90.24.115 58. PMC 48023.PMID 8265589.

4. Roberts, S.O. (1969). Pityriasis versicolor: a clinical and mycological investigation. $\mathrm{Br} J$ Dermatol, 81; 315-26.

5. ST. (1986). The Biology of Marine Fungi. Cambridge, UK: Cambridge University Press. p. 76. ISBN 0-521-30899-2.

6. Roberts, S.O. (1969). Pityriasis versicolor: a clinical and mycological investigation. $\mathrm{Br} J$ Dermatol, 81; 315-26.

7. Luis, J. (2009). Pathogenesis of dermatophytosis and tinea versicolor. Clinics in Dermatology, 28(2); 185-9.
8. ST. (1986). The Biology of Marine Fungi. Cambridge, UK: Cambridge University Press. p. 76. ISBN 0-521-30899-2.

9. https://www.healthline.com/health/agespots\#outlook.

10. Ratnavel, R.C., Squire, R.A., Boorman, G.C. (2007). "Clinical efficacies of shampoos containing ciclopirox olamine $(1.5 \%)$ and ketoconazole $(2.0 \%)$ in the treatment of seborrhoeic dermatitis". $J$ Dermatolog Treat, $18 \quad$ (2): $\quad 88-96$. doi:10.1080/16537150601092944. PMID 17520465 .

11. Jaya, R. K. (2014). Antifungal Agents: New Approach for Novel Delivery Systems. J. Pharm. Sci. \& Res, 6(5), 2014, 229-235.

12. Dr Colin Tidy, Reviewed by Dr Laurence Knott | Last edited 17 Mar 2021 | Meets Patient's editorial guidelines.

13. Khatry. (2010). Novel drug delivery systems for antifungal therapy. Int J Pharm Pharm Sci, 2; 4, 69

14. Himesh, S. (2021). Hydrogels as Effective drug Delivery Systems, SAR J Anat Physiol, 2(2), 17-21.

15. Himesh, S. (2021). Corona: Impact of Non-Living Virus to Living World. Saudi J Med Pharm Sci, 7(10); 496-503.

Cite This Article: Lalita Bansal \& Ashish Dhiman (2022). A Brief Review of Fungal Infection- Pityriasis Versicolor. East African Scholars J Med Surg, 4(1), 19-23. 